\title{
Material Selection for Interfacial Bond Layer in Electronic Packaging
}

\author{
D.Sujan, L. Vincent and Y. W. Pok \\ Faculty of Engineering and Science, Curtin University Malaysia \\ CDT 250, 98009 Miri, Sarawak, Malaysia
}

\begin{abstract}
In electronic packaging, typically two or more thin dissimilar plates or layers are bonded together by an extremely thin adhesive bond layer. Electronic assemblies are usually operated under high power conditions which predictably produces a high temperature environment in the electronic devices. Therefore, thermal mismatch shear and peeling stress inevitably arise at the interfaces of the bonded dissimilar materials due to differences in Coefficient of Thermal Expansion (CTE) typically during the high temperature change in the bond process. As a result, delamination failure may occur during manufacturing, machining, and field use. As such, these thermo-mechanical stresses play a very significant role in the design and reliability of the electronic packaging assembly. Consequently, critical investigations of interfacial stresses under variable load conditions in composite structure can result in a better design of electronic packaging with higher reliability and minimize or eliminate the risk of functional failure. In order to formulize bond material selection, analytical studies are carried out in order to study the influence of bond layer parameters on interfacial thermal stresses of a given package. These parameters include Coefficient of thermal expansion (CTE), poison's ratio, temperature, thickness, and stiffness (compliant and stiff) of the bond layer. From the study, stiffness and bond layer thickness are identified as the key parameters influencing interfacial shearing and peeling stresses. The other parameters namely CTE, poisons ratio has shown insignificant influence on interfacial stresses due to the very thin section of bond layer compared to the top and bottom layers. The results also show that the interfacial stresses increases proportionally with the increase of temperature in the layers. Therefore, it is very important that the temperature is maintained as low as possible during the chip manufacturing and operating stages. Since only two parameters namely stiffness and bond layer thickness are identified as the key parameters, the interface thermal mismatch stresses can be reduced or eliminated by controlling these two parameters only. Therefore the identification of suitable bond layer parameters selection with reasonable accuracy is possible even without performing optimization process. Finally, this paper proposes a Metal Matrix Composite (MMC) bond material selection approach using rule of mixture material design. The outcome of this research can be seen in the forms of practical and beneficial tools for interfacial stress evaluation and physical design and fabrication of layered assemblies. The Engineers can utilize this research outcome in conjunction with guidelines for electronic packaging under variable thermal properties of layered composites.
\end{abstract}

\section{Introduction}

In electronic packaging, typically two or more thin dissimilar plates or layers are bonded together by an extremely thin adhesive bond layer. Electronic assemblies are usually operated under high power conditions which predictably produces a high temperature environment in the electronic devices. Therefore, thermal mismatch shear and peeling stress inevitably arise at the interfaces of the bonded dissimilar materials due to differences in Coefficient of Thermal Expansion (CTE) typically during the high temperature change in the bonding process. As a result, delamination failure may occur during manufacturing, machining, and field use. As such, these thermo-mechanical stresses play a very significant role in the design and reliability of the electronic packaging assembly. Consequently, critical investigations of interfacial stresses under variable load conditions in composite structure can result in a better design of electronic packaging with higher reliability and minimize or eliminate the risk of functional failure [1-10].

The selection of electronic packaging materials (including bond layer) for optimum performance under thermal loading is a challenging task to minimize or eliminate the risk of structural failure. Therefore, there is a compulsion to understand the mechanism of interfacial stresses development in electronic packaging [7, 11]. Bi- 
layered analytical model for interfacial shear and peeling stress has been developed by Suhir [12] using integrodifferential equation. Suhir expressed the compatibility condition at the interface in terms of strain. Sujan et al $[15,7,13-15]$ had developed a simple solution using a second order differential equation approach. Sujan used the compatibility at the interface in terms of displacement. For both Suhir and Sujan, Models are mathematically equivalent and thus lead to the same solution. The effect of bond layer properties and geometry would be another important concern in developing an optimized solution in electronic packaging.

The conventional leaded bond material is found to have poor thermal mismatch resistance. Therefore, in recent years, there are novel efforts in the new development on lead free bond materials. On the other hand, particulate reinforced light Metal Matrix Composites (MMC) have shown great promise due to their outstanding tailor-made mechanical and physical properties.

This research is proposed to formulate a lead free bond material selection approach in electronic packaging to estimate the best possible mechanical and physical properties of the bond material in relation to the packaging materials in order to minimize thermal mismatch stresses. Subsequently, MMC bond material selection strategy is developed by using the rule of mixture (ROM) design approach [16]. ROM is a method which is based on the assumption that a composite property is the volume weighted average of the total constituents of the material. MMC approach can be utilized later (which is out of the scope of this project) in order to synthesize the tailored sustainable bond material recommended by the reference model.

The outcome of this research is in the forms of practical and beneficial tools for interfacial stress evaluation and physical design of layered assemblies. The Engineers can utilize this reference model in conjunction with guidelines for electronic packaging under variable thermal properties of layered composites.

In this study a closed form model of bi-layered assembly is used with the up-to-date bond layer shear stress compliance expression [5]. The key bond layer properties namely Young's modulus, coefficient of thermal expansion, Poisson's ratio, and physical parameters like temperature and thickness are considered for interfacial stress evaluation.

\section{Analytical Model}

The same analytical model which has been used in paper 1 (Title: Bond layer properties and geometry effect on interfacial thermo-mechanical stresses in bi-material electronic packaging assembly) in this conference is utilized for bond material selection, and design approach. Therefore, only brief discussion of the model and the findings of the paper 1 will be discussed here for the process. Since maximum stressed are recorded at the location of $\mathrm{x} / \mathrm{L}=1$ (edge), only results related to this location will be considered.
Figure 1(a) shows an arbitrary location of the model in 2-dimensional form. Figure 1(b) shows the free body diagram of the full length of the model. The model is considered to be a unit of width in a direction perpendicular to the plane of the paper and the forces and moments are defined with respect to the unit width.

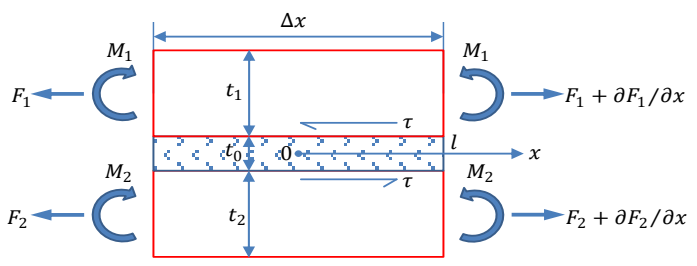

(a)

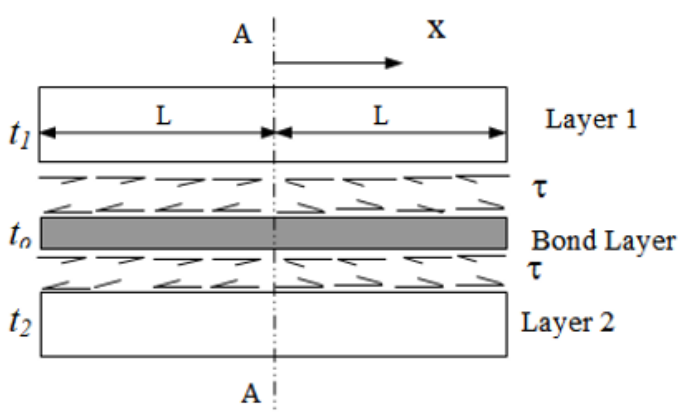

(b)

Figure 1. (a) Bi-material assembly and (b) free-body diagram of the model

Symbols and their meanings in this paper:

Material or layer number, $i=1,2 ; \mathrm{E}=$ Young's modulus $\left(\mathrm{N} / \mathrm{m}^{2}\right) ; t_{\mathrm{i}}=$ Thickness $(\mathrm{m}) ; \Delta T=120^{\circ} \mathrm{C}$ $\alpha_{i}=$ Coefficient of thermal Expansion $\left(1 /{ }^{\circ} \mathrm{C}\right)$; $v_{i}=$ poison's ratio; $R=$ Radius of curvature;

The key assumptions as follows:

- Each layer can be regarded as Bernoulli beam

- No external force acting among them.

- Axial force due to thermal loading varies along the length of the bonded layers.

The shear stress $\tau(\mathrm{x})$ is given by,

$$
\tau=\frac{\Delta T\left(\alpha_{1}-\alpha_{2}\right)}{K \kappa \cosh (\kappa L)} \sinh (\kappa x)
$$

The peeling stress $\mathrm{P}(\mathrm{x})$ expression is given by,

$$
P=\frac{\left(t_{1} D_{2}-t_{2} D_{1}\right)}{2 D} \frac{\Delta T\left(\alpha_{1}-\alpha_{2}\right)}{K \cosh (\kappa L)} \cosh (\kappa x)
$$

Where $t=t_{1}+t_{2}+2 t_{0}, \lambda=\lambda_{1}+\lambda_{2}+\frac{t\left(t_{1}+t_{2}\right)}{4 D}$, and $K=K_{1}+K_{2}+K_{0}$ and $\kappa=\sqrt{\frac{\lambda}{K}}$ 


\section{Numerical example:}

Table 1 shows the parameters used to calculate the interfacial stresses by using the analytical approach. The length of the assembly is $2 L=0.005 \mathrm{~m}$. The temperature changes, $\Delta \mathrm{T}$ is taken at $120^{\circ} \mathrm{C}$ in this computation.

Table 1. Material properties and dimension

\begin{tabular}{|c|c|c|c|c|}
\hline Material & $\begin{array}{c}\text { Young's } \\
\text { Modulus, } E_{i} \\
(\mathrm{GPa})\end{array}$ & $\begin{array}{c}\mathrm{CTE}, \alpha_{i} \\
\left({ }^{\circ} \mathrm{C}\right), 10^{-}\end{array}$ & $\begin{array}{c}\text { Poisson's } \\
\text { Ratio }\end{array}$ & $\begin{array}{c}\text { Thickness } \\
t_{i}, \mathrm{~mm}\end{array}$ \\
\hline Die & 110 & 2.9 & 0.31 & 0.40 \\
\hline $\begin{array}{c}\text { Die } \\
\text { attach }\end{array}$ & 141 & 22 & 0.28 & 0.20 \\
\hline $\begin{array}{c}\text { Bond } \\
\text { layer }\end{array}$ & $10-70$ & $5-25$ & $0.25-0.33$ & $0.00-0.08$ \\
\hline
\end{tabular}

\section{Results and Discussion}

The shearing stress and peeling stress are calculated using eq. (1) and eq. (2) respectively. The results are plotted in Figure 2 to Figure 5 and Table 3 to Table 4.The interfacial stresses are tabulated from $\mathrm{x} / \mathrm{L}=0.91-1.0$, since the stress values are significantly high in the vicinity of the edge. The maximum shearing stress and peeling stress are recorded at the free end $(x / L=1.0)$ as expected.

\subsection{Young's Modulus (Stiffness) Effect}

Table 2 represents shearing and peeling stresses for different values of Young modulus $\left(E_{0}\right)$ at location $\mathrm{x} / \mathrm{L}=$ 1. The Young modulus of bond layer, $E_{0}$ is varied from 10 to $70 \mathrm{MPa}$ at the interval of $10,20,30,40$, and 70 $\mathrm{MPa}$. From the Table 2, it can be observed that the shearing stress is tensile while peeling stress is compressive in nature along the interface as suggested in theory. It is observed that both the shearing and peeling stress increase with the increase of Young's modulus of bond layer. For instance an increase of $60 \%$ in shear stress and $83 \%$ in peeling stress are observed for an inresae of $E_{0}$ from 10 to $70 \mathrm{MPa}$. Thus, it indicates that a more compliant bond will likely to result in smaller interfacial stress compared to a stiffer bond. However, there might be necessary to compromise between compliant and stiff bond due to the fact that more compliant bond is likely to deform easily [4].

Table2. Shear and peeling stress along the interface with Young's Modulus as parameter

\begin{tabular}{|c|c|c|c|c|c|}
\hline $\begin{array}{c}\text { Young's Modulus, } \\
E_{0}(\mathrm{GPa})\end{array}$ & $\mathbf{1 0}$ & $\mathbf{2 0}$ & $\mathbf{3 0}$ & $\mathbf{4 0}$ & $\mathbf{7 0}$ \\
\hline $\begin{array}{c}\text { Shear Stress } \\
(\mathrm{MPa})\end{array}$ & -43.9 & -54.4 & -56.0 & -63.5 & -69.9 \\
\hline $\begin{array}{c}\text { Peeling Stress } \\
(\mathrm{MPa})\end{array}$ & 14.5 & 19.7 & 22.4 & 24.1 & 26.6 \\
\hline
\end{tabular}

\subsection{Thickness effect}

Table 3 compares shearing and peeling stress with bond layer thickness, $t_{0}$ as a parameter at the location $x / L=1$

\begin{tabular}{|c|c|c|c|c|c|}
\hline $\begin{array}{c}\text { Thickness } \\
\mathrm{t}_{\mathrm{i}}, \mathrm{mm}\end{array}$ & $\mathbf{0}$ & $\mathbf{0 . 0 2}$ & $\mathbf{0 . 0 4}$ & $\mathbf{0 . 0 6}$ & $\mathbf{0 . 0 8}$ \\
\hline $\begin{array}{c}\text { Shear Stress } \\
(\mathrm{MPa})\end{array}$ & -83.2 & -77.1 & -71.8 & -67.3 & -63.3 \\
\hline $\begin{array}{c}\text { Peeling Stress } \\
(\mathrm{MPa})\end{array}$ & 30.9 & 27.8 & 25.2 & 23.1 & 21.3 \\
\hline
\end{tabular}

From Table 3, the shearing and peeling stresses decrease with the increase of compliant bond layer thickness. For instance, the shearing and peeling stresses decreased nearly $24 \%$ and $31 \%$ for an increase of $h_{0}$ from 0 to 0.08 $\mathrm{mm}$. The increased bond layer thickness acts as a cushion between the layers which reduces the interfacial shear stress along the interface. Therefore, a higher value of bond layer thickness would be suggested in the flip-chip packaging design. However, the increased bond thickness appears to be another concern for the increased overall space and cost of material.

\subsection{Poisson's ratio effect}

Table 4 represents the shear and peeling stress values at location $\mathrm{x} / \mathrm{L}=1$ (edge) with Poisson's Ratio varied in the range of $0.25-0.33$. It can be observed that the both shear and peeling stress changes very slightly due to the variation of Poisson's Ratio.

Table 4. Stresses at location $\mathrm{x} / \mathrm{L}=1$ for different Poisson's ratio

\begin{tabular}{|c|c|c|c|c|c|}
\hline $\begin{array}{c}\text { Poisson's } \\
\text { Ratio, } v\end{array}$ & $\mathbf{0 . 2 5}$ & $\mathbf{0 . 2 7}$ & $\mathbf{0 . 2 9}$ & $\mathbf{0 . 3 1}$ & $\mathbf{0 . 3 3}$ \\
\hline $\begin{array}{c}\text { Shear Stress } \\
(\mathrm{MPa})\end{array}$ & -43.9 & -43.7 & -43.5 & -43.2 & $\begin{array}{r}- \\
\hline 3.0\end{array}$ \\
\hline $\begin{array}{c}\text { Peeling Stress } \\
(\mathrm{MPa})\end{array}$ & 29.9 & 29.8 & 29.7 & 29.6 & 29.5 \\
\hline
\end{tabular}

Thus, Poisson ratio of bond layer do not play significant role in reducing interfacial stresses in layered structure. From the above observation it can be concluded that the effect of Poisson ratio in bond layer may not be essential to consider in predicting stresses development at the interface.

\subsection{Thermal expansion coefficient effect}

From eq. (1) and Eq. (2), it can be observed that the coefficient of thermal expansion of bond layer term is missing or has no effect in shearing and peeling stress expressions for with bond layer consideration. This is due to the fact that the bond layer is extremely thin compared to the two adhere layers. Therefore, it does not contribute much in terms of expansion and compression of the overall package. Therefore, it can be concluded that the coefficient of thermal expansion of the bond layer is not necessary to consider in predicting stresses development at the interface.

\subsection{Temperature effect}

From eq. (1) and eq. (2), it can be observed that the bond layer term is also missing in shearing and peeling stress expressions for with bond layer consideration. This is due 
to the fact that the bond layer is extremely thin compared to the two adhere layers. Therefore, it can be logically assumed that the bond layer temperature will be same as the overall package.

Table 5. Stresses at location $x / L=1$ for different temperature

\begin{tabular}{|c|c|c|c|c|c|}
\hline Temperature, ${ }^{\circ} \mathrm{C}$ & $\mathbf{6 0}$ & $\mathbf{8 0}$ & $\mathbf{1 0 0}$ & $\mathbf{1 2 0}$ & $\mathbf{1 4 0}$ \\
\hline $\begin{array}{c}\text { Shear Stress } \\
(\mathrm{MPa})\end{array}$ & - & -42.3 & -52.9 & -63.5 & -74.1 \\
\hline $\begin{array}{c}\text { Peeling Stress } \\
(\mathrm{MPa})\end{array}$ & 17.4 & 23.2 & 29.0 & 34.8 & 40.6 \\
\hline
\end{tabular}

Nevertheless, Table 5 clearly indicates that the temperature is a very significant factor in stress development in the interface. For instance, shear stress increases $233 \%$ for an increment of temperature from $60^{\circ} \mathrm{C}$ to $120^{\circ} \mathrm{C}$ at the edge of the package. Therefore, it can be concluded that the temperature should be as low as possible during manufacturing and operation of electronic packages to avoid mechanical and functional failure.

\section{The proposed bond material selection approach:}

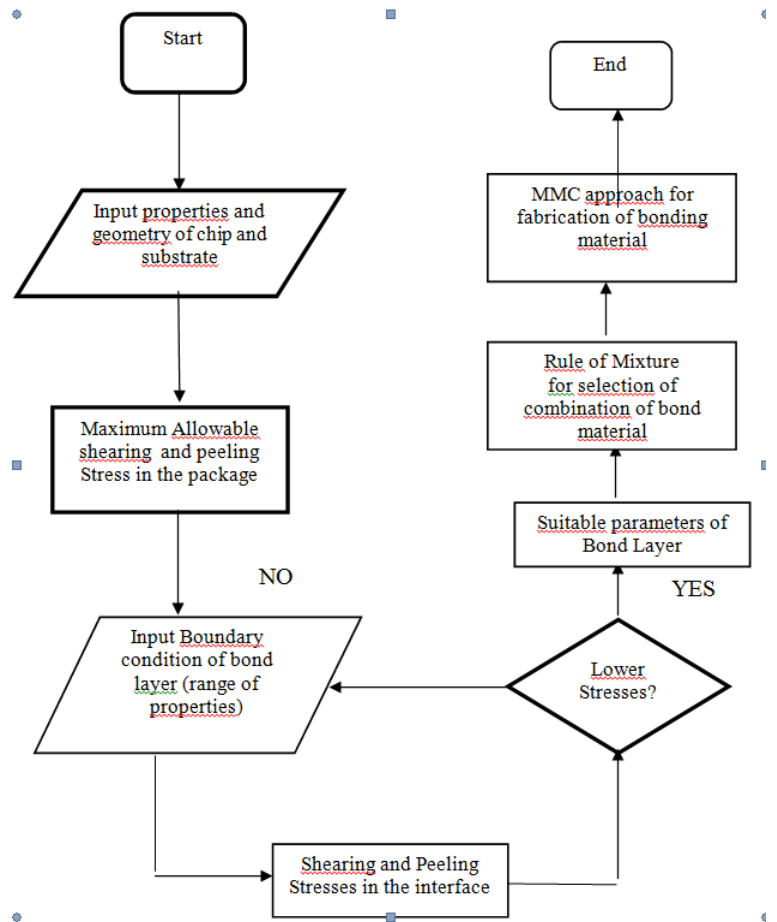

Figure 2: Rule of Mixture design for interfacial bond layer selection

\subsection{The detail step-by-step approach for bond material selection, design and fabrication}

Step 1: Key in properties and geometry of Die and Die Attach of an arbitrary bi-layered package

Refer to Table 1

Step 2: Key in range of bond layer parameters

Refer to Table 1
Step 3: Key in the interfacial shearing and peeling stress expressions as follows:

The shear stress $\tau(\mathrm{x})$ is given by,

$$
\tau=\frac{\Delta T\left(\alpha_{1}-\alpha_{2}\right)}{K \kappa \cosh (\kappa L)} \sinh (\kappa x)
$$

The peeling stress $\mathrm{P}(\mathrm{x})$ expression is given by,

$$
P=\frac{\left(t_{1} D_{2}-t_{2} D_{1}\right)}{2 D} \frac{\Delta T\left(\alpha_{1}-\alpha_{2}\right)}{K \cosh (\kappa L)} \cosh (\kappa x)
$$

Step 4: Identify bond layer properties and geometry parameter as follows:

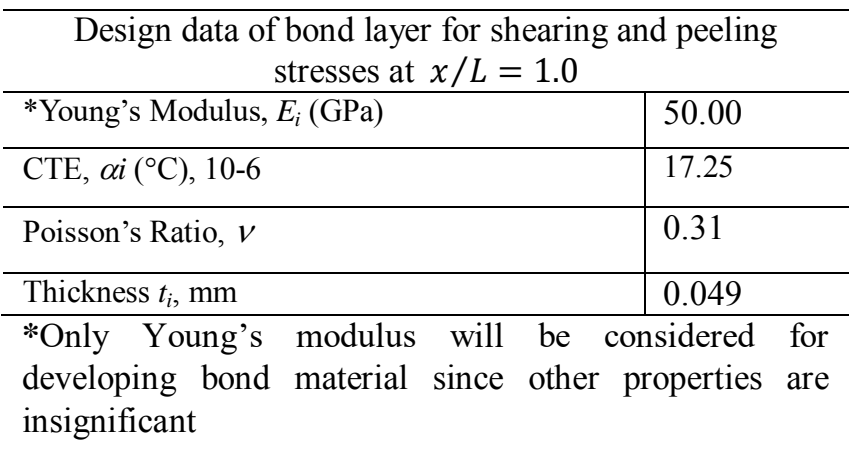

Step 5: Find the volume fraction of material combination (alloy) using rule of mixture

The parametric studies which had been carried out earlier concluded that the dominant factors of bond layer in minimizing interfacial stresses in the attached layers are: elastic modulus, $E_{i}$ and thickness, $t_{i}$. Since the thickness of bond layer is a physical property that can be altered, therefore the application of rule of mixture in selecting the material combination for bond layer is focusing on elastic modulus.

The equation for rule of mixture is, $E_{c}=f E_{A}+(1-f) E_{B}$

$f=\frac{V_{f}}{V_{f}+V_{m}}$ (volume fraction); where $E_{A}=$ Property of material $A$ and $E_{B}=$ Property of material $B$

Table 6. Candidate Lead-free bonding materials in electronic packaging

\begin{tabular}{l|c} 
Material & Young's Modulus, $E_{i}(\mathrm{GPa})$ \\
\hline Tin (Sn) & 43.0 \\
Silver (Ag) & 83 \\
\hline Antimony (sb) & 55 \\
Zirconium (Zr) & 88 \\
\hline Zinc (Zn) & 108 \\
Aluminum (al) & 69
\end{tabular}




\begin{tabular}{l|c}
\hline Gold (Au) & 79 \\
Platinum (Pt) & 168 \\
\hline Copper (Cu) & 117 \\
Indium (In) & 11.51 \\
\hline Bismuth (Bi) & 34.02 \\
Cadmium (Cd) & 62.5
\end{tabular}

As shown in the Table 6 above, no material from the list exhibits the exact elastic modulus for optimized interfacial stresses in the package, which is $50.0 \mathrm{GPa}$ in Example 1. Therefore, composite or alloy will be a better alternative solution to produce bonding material with desired properties. Examples of alloy/combination used in electronic packaging are: 1. Tin-antimony alloy; 2 . Tin-silver alloy; 3. Zirconium-tin alloy; 4. Zincaluminium alloy; 4. Zinc-aluminium alloy; 5. Goldplatinum alloy; 7. Silver-copper alloy; 8. Zinc-Cu-Ti alloy ; 9. Zinc-copper alloy ; 10. Gold-Tin

\section{Example combination 1: Tin-antimony alloy}

$$
E_{c}=f E_{A}+(1-f) E_{B}
$$

$E_{C}=$ Elastic modulus of desired bonding material, 50 $\mathrm{GPa} ; E_{A}=$ Elastic modulus of tin, $43.0 \mathrm{GPa} ; E_{B}=$ Elastic modulus of antimony, $55.0 \mathrm{GPa}$

$$
f=\frac{E_{c}-E_{B}}{E_{A}-E_{B}}=\frac{50.0-55.0}{43.0-55.0}=0.417
$$

Therefore, $41.7 \%$ of tin and $59.3 \%$ of antimony is required to manufacture tin-antimony alloy bond layer with desired Young modulus, which is $50.0 \mathrm{GPa}$ in order to minimize the interfacial stresses in the silicondiamond electronic package.

Step 6: Fabrication of MMC composite material based on the combination from Rule of Mixture

\section{Conclusions}

In this research paper, a methodology is proposed for lead free bond material selection approach. Analytical studies were carried out in order to study the influence of bond layer parameters on interfacial thermal stresses of a given package. From the study, stiffness and bond layer thickness were identified as the key parameters influencing interfacial shearing and peeling stresses. The other parameters namely CTE, poisons ratio has shown insignificant influence on interfacial stresses due to the very thin section of bond layer compared to the top and bottom layers. From the analytical model, it is also obvious that the interfacial stresses increase proportionally with the increase of temperature in the layers. Therefore, temperature should be maintained as low as possible during the chip manufacturing and operating stages. Since only stiffness and bond layer thickness were identified as the key parameters, the interface thermal mismatch stresses can be reduced or eliminated by controlling these two parameters only. Therefore the identification of suitable bond layer parameters selection with reasonable accuracy is possible even without performing optimization process. Finally, this paper proposed a Metal Matrix Composite (MMC) bond material selection approach using rule of mixture material design. The outcome of this research can be seen in the forms of practical and beneficial tools for interfacial stress evaluation and physical design and fabrication of layered assemblies. The Engineers can utilize this research outcome in conjunction with guidelines for electronic packaging under variable thermal properties of layered composites.

\section{Acknowledgement}

The authors thankfully acknowledge the research facilities and infrastructure provided by the Curtin University Malaysia and the financial assistance provided by the Ministry of Higher education (Malaysia) under FRGS scheme, Grant reference Code: FRGS/2/2013/SG06/CURTIN/02/1

\section{References}

1. Timoshenko. S. (1925). Analysis of Bi-Metal Thermostats. Journal of the Optical Society of America.11, pp. 233-255

2. Tummala, R. (2001). Fundamentals of microsystems packaging . McGraw Hill Professional.

3. Suhir, E. (2017). Flip-chip assembly: Is the bimaterial model acceptable? Journal of Materials Science: Materials in Electronics, 28(21), 1577515781. doi:10.1007/s10854-017-7471-8

4. Moore, G. E. (1998). Cramming more components onto integrated circuits. Proceedings of the IEEE, 86(1), 82-85. doi:10.1109/JPROC.1998.658762

5. Sujan, D., Woldemichael, D. E., Murthy, M. V. V., \& Seetharamu, K. N. (2011). Effect of bond layer on bimaterial assembly subjected to uniform temperature change. Journal of Electronic Packaging, Transactions of the ASME, 133(4) doi:10.1115/1.4005294

6. Brown, W. D. (1998). Advanced Electronic Packaging with Emphasis on Multichip Modules. ed.

7. Sujan, D., Pang, X. B., Rahman, M. E., \& Reddy, M. M. (2014). Performance of solder bond on thermal mismatch stresses in electronic packaging assembly doi:10.4028/www.scientific.net/MSF.773-774.242

8. Huang, Y.W., Lin, Y. M., Zhan. C.J. Assembly of 3D Chip Stack with $30 \mu \mathrm{m}$-Pitch Micro Interconnects Using Novel Arrayed-Particles Anisotropic Conductive Film. Proceedings of the 2013 Electronic Components and Technology Conference, pp. 71-76.

9. Suhir, E. (2014). Thermal stress in through-siliconvias: Theory-of-elasticity approach. Microelectronics Reliability, 54(5), 972-977. doi:10.1016/j.microrel. 2014.01.004

10. Gao, L., Chen, X., \& Gao, H. (2015). Interfacial thermal stresses in ACF bonding assembly. Microelectronics Reliability, 55(7), 1089-1096. doi:10.1016/j.microrel.2015.04.004 
11. Suhir, E. (1989). Interfacial stresses in bimetal thermostats. Journal of Applied Mechanics, Transactions ASME, 56(3), 595-600. doi:10.1115/1.3176133

12. Suhir, E. (1986). CALCULATED THERMALLY INDUCED STRESSES IN ADHESIVELY BONDED AND SOLDERED ASSEMBLIES. Paper presented at the 383-392.

13. Sujan, D., Murthy, M. V. V., Seetharamu, K. N., \& Hassan, A. Y. (2005). Complete model for interfacial stresses of a two layered structure. Paper presented at the Proceedings of the 6th International Conference on Thermal, Mechanical and Multi-Physics Simulation and Experiments in Micro-Electronics and Micro-Systems - EuroSimE 2005, , 2005 454461. doi:10.1109/ESIME.2005.1502848

14. Sujan, D., Murthy, M. V. V., \& Seetharamu, K. N. (2011). Improved tri-layered interfacial stress model with the effect of different temperatures in the layers. Archive of Applied Mechanics, 81(5), 561-568. doi:10.1007/s00419-010-0437-4

15. Sujan, D., Murthy, M. V. V., Seetharamu, K. N., \& Hassan, A. Y. (2005). Engineering model for interfacial stresses of a heated bimaterial structure with bond material used in electronic packages. Journal of Microelectronics and Electronic Packaging, 2(2), 132-141. doi:10.4071/1551-48972.2.132

16. Wu, H. F., Wu, L. L., Slagter, W. J., \& Verolme, J. L. (1994). Use of rule of mixtures and metal volume fraction for mechanical property predictions of fibrereinforced aluminium laminates. Journal of Materials Science, 29(17), 4583-4591. doi:10.1007/ BF00376282 